\title{
„CHildhood Allergy and tolerance: bioMarkers and Predictors" (CHAMP) -A call for prediction and quality of life
}

\author{
Jana Eckert ${ }^{1}$, Julia Kahle ${ }^{2}$, Andreas Böck ${ }^{1}$, Kathrin Zeber ${ }^{1}$, Kathrin Urner $^{1}$, Wolfgang \\ Greiner $^{3}$, Simone Kreimeier ${ }^{3}$, Kirsten BEYER ${ }^{4}$, Josefine Dobbertin-Welsch ${ }^{4}$, Eckard \\ Hamelmann $^{3}$, Ines Gellhaus ${ }^{3}$, Christina Schorlemer ${ }^{3}$, Michael Kabesch ${ }^{5}$, Parastoo \\ Kheiroddin $^{5}$, Erika von Mutius ${ }^{1}$, Martin Depner ${ }^{6}$, Daniel Walter ${ }^{1}$, Gesine Hansen ${ }^{7}$, \\ Stephanie DeStefano ${ }^{7}$, Sabine Schnadt ${ }^{2}$, and Bianca Schaub ${ }^{1}$ \\ ${ }^{1}$ Dr von Haunersches Kinderspital Kinderklinik und Kinderpoliklinik der Ludwig \\ Maximilian Universitat Munchen \\ ${ }^{2}$ German Allergy and Asthma Foundation \\ ${ }^{3}$ Bielefeld University \\ ${ }^{4}$ Charite University Hospital Berlin \\ ${ }^{5}$ University of Regensburg \\ ${ }^{6}$ Helmholtz Center Munich German Research Center for Environmental Health \\ ${ }^{7}$ Hannover Medical School
}

January 5, 2021

\begin{abstract}
Background: Allergic diseases are the most prevalent chronic childhood diseases resulting in a massive societal and economic burden for the community and a significant reduction of health-related quality of life (HRQoL) for affected families. The project CHAMP (CHildhood Allergy and tolerance: bioMarkers and Predictors) was funded in 2017 by the German Federal Ministry for Education and Research. Methods: CHAMP investigates the determinants of different allergic diseases from birth to adolescence to identify clinically relevant biomarkers predicting onset, progression, remission and severity. Data on HRQoL and patient's needs and requirements were collected, supported by the German Asthma and Allergy Association (DAAB). Using validated questionnaires and outpatient visits, eight subprojects analysed allergic diseases in epidemiological or clinical cohorts (more than 2500 children/adolescents), sampling numerous biomaterials to assess omics on several levels. Murine models disentangled underlying mechanisms of early tolerance, translating findings from the cohorts to models and vice versa. Results: The DAAB survey, including 851 participants, showed that $83 \%$ were interested in prediction of the course of different current allergic diseases and future manifestation. $86 \%$ of participants considered doctor's specialized training and their education as highly important, over $70 \%$ chose research for allergy understanding and prevention as critical. CHAMP addresses these needs. Common SOPs have been established and recruitment is ongoing. Conclusion: The DAAB patient survey confirmed the critical need for translational allergy research. CHAMP envisions to predict onset, tolerance and remission of allergic diseases and to identify disease sub-phenotypes for future development of preventive strategies and novel avenues for therapeutic options.
\end{abstract}

\section{Hosted file}

20201223_CHAMP Publication_main.pdf available at https://authorea.com/users/387299/articles/ 502471--childhood-allergy-and-tolerance-biomarkers-and-predictors-champ-a-call-forprediction-and-quality-of-life

\section{Hosted file}


20201222_CHAMP Publication_ Tables.pdf available at https://authorea.com/users/387299/ articles/502471--childhood-allergy-and-tolerance-biomarkers-and-predictors-champ-acall-for-prediction-and-quality-of-life
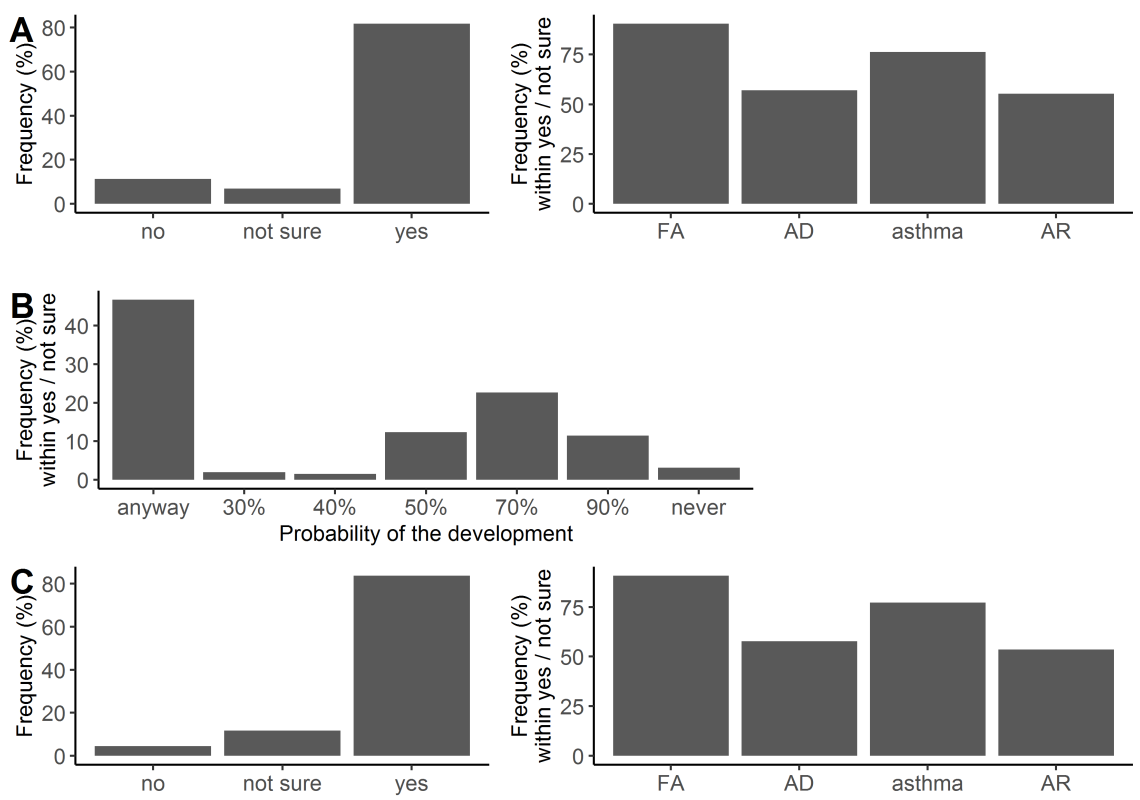

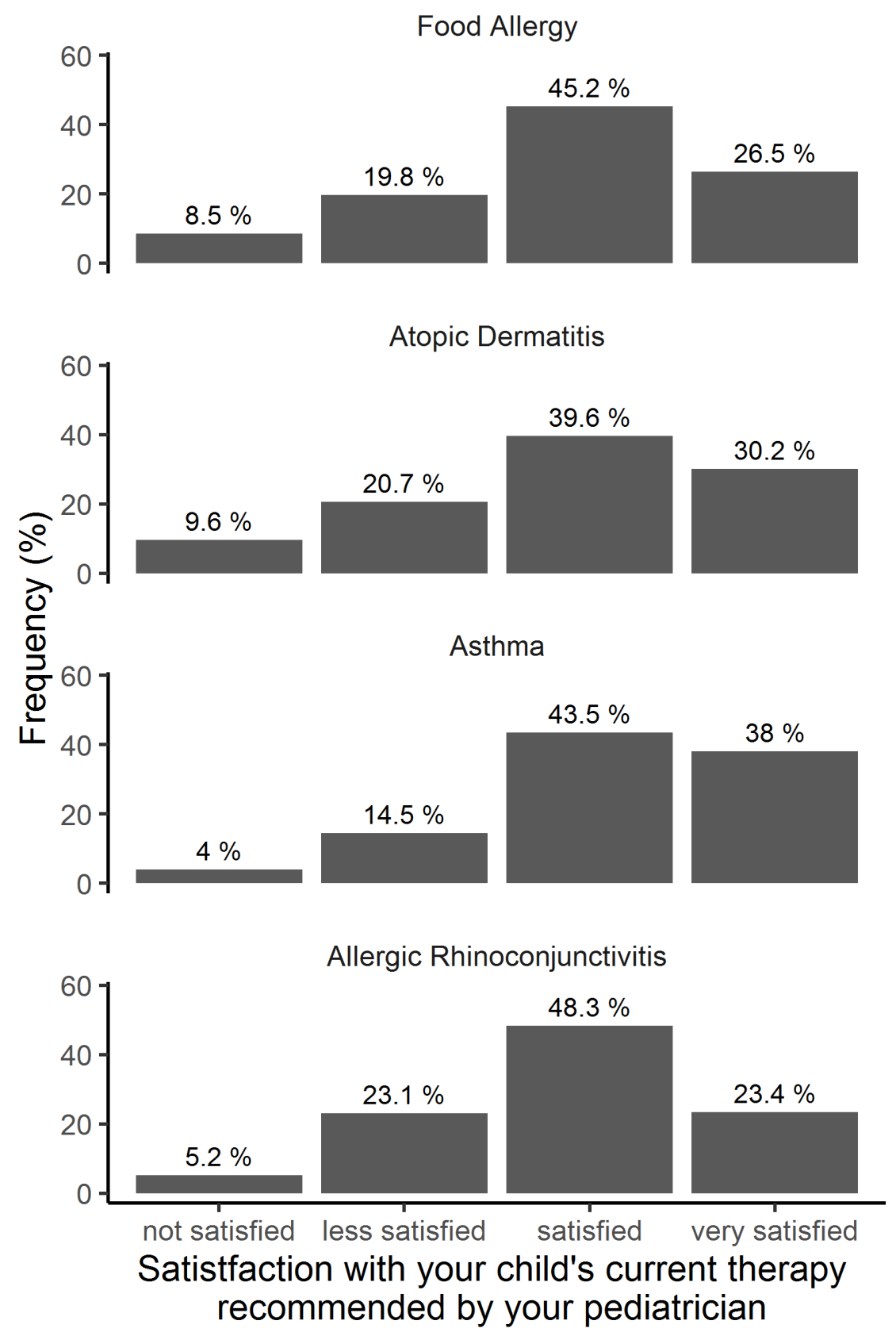


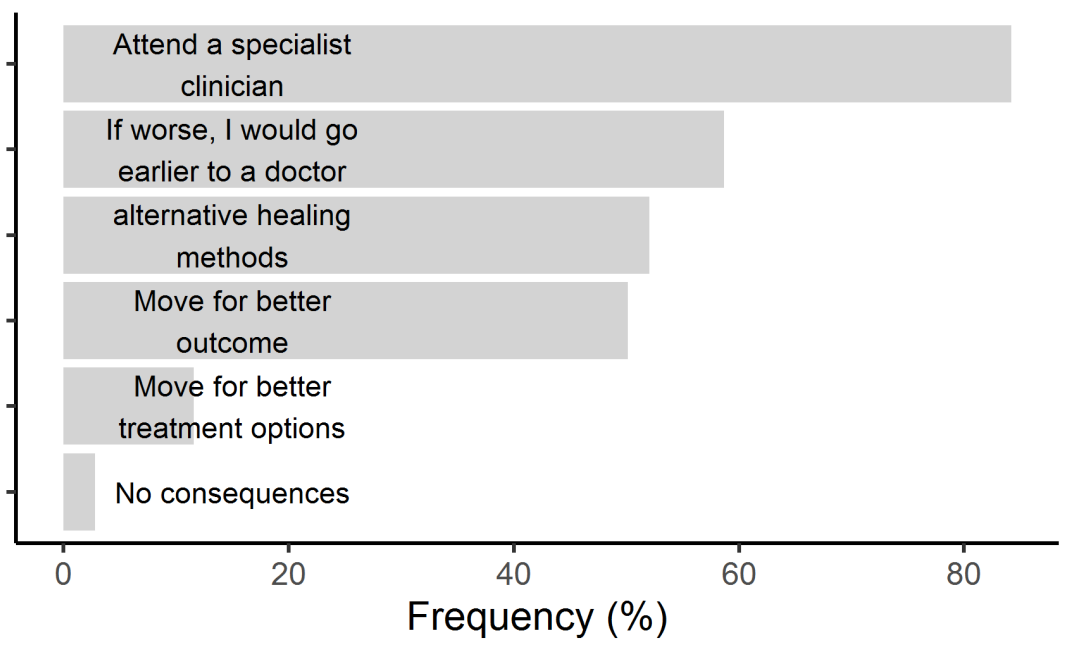

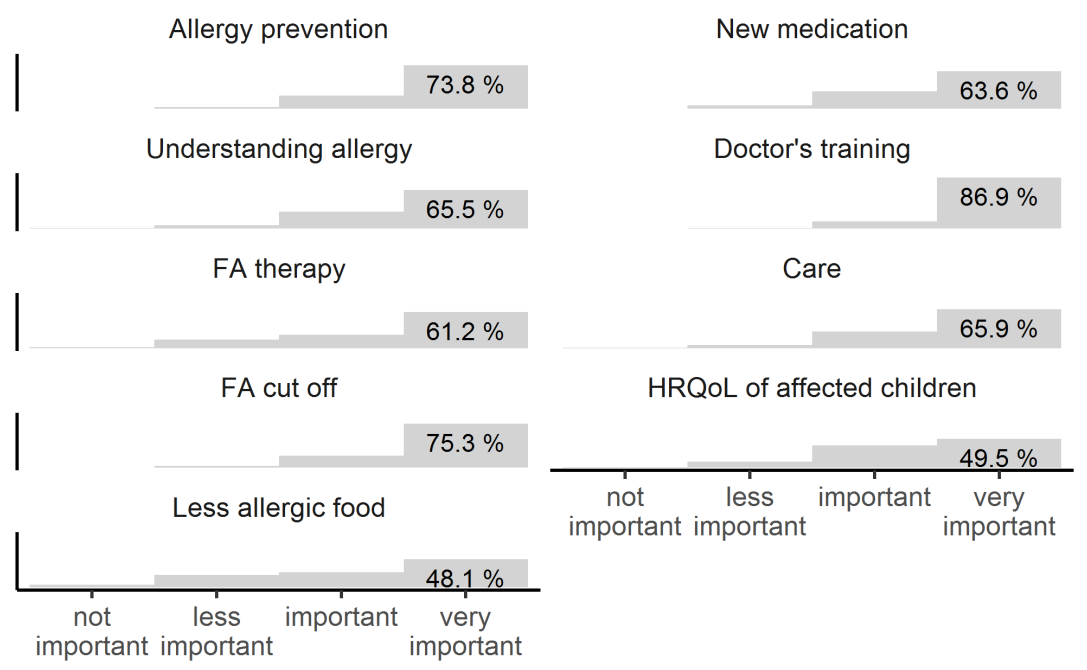




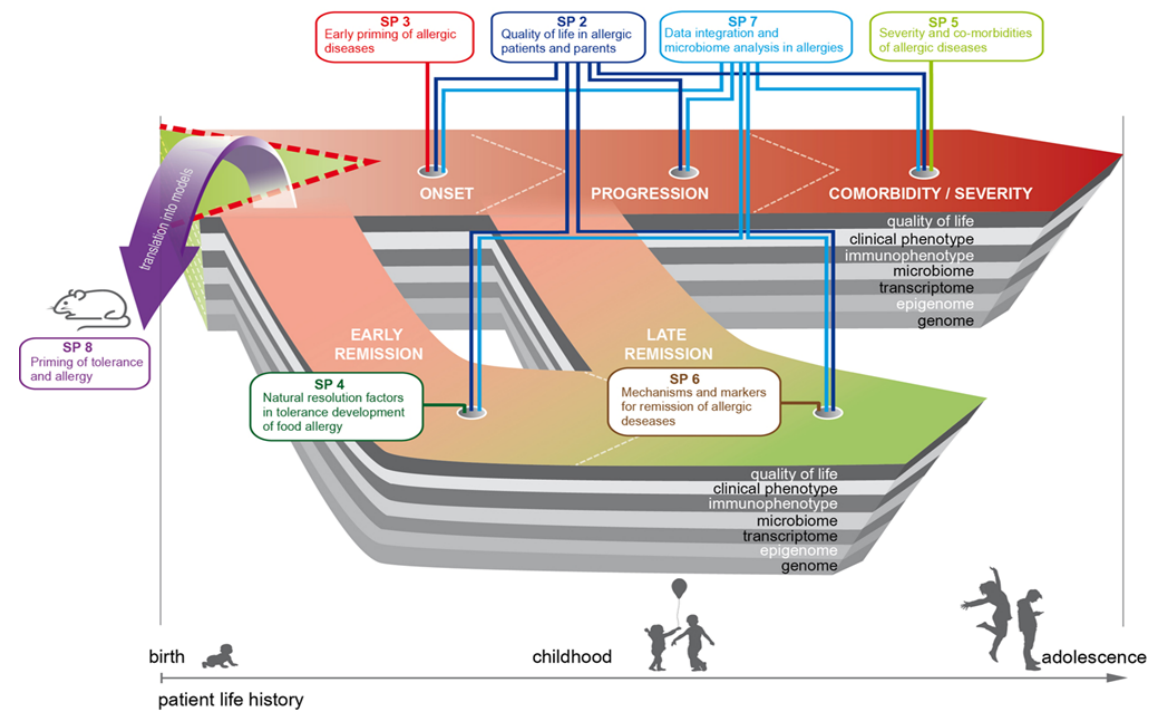

